\title{
Mineral Analyses \& Implications on the Dispersion of Bismuth in the Supergene Environment of Eastern Australia.
}

\author{
T, Murphy ${ }^{1}$, A. J. Roper ${ }^{1}$, S. Hager ${ }^{1}$, R. Wuhrer ${ }^{2}$, P. Leverett and P. A. Williams \\ ${ }^{1}$ School of Science and Health, University of Western Sydney, NSW 2751, Australia. \\ 2.Advanced Materials Characterisation Facility, University of Western Sydney, Australia.
}

In the Australian context, bismuth minerals are important constituents, associated with Mo, W and Sn, of highly acidic and very rich, low tonnage, deposits of the eastern ranges of Australia. Bi has been used extensively as a pathfinder element in geochemical exploration for a variety of such deposits and others and therefore it is important to understand its behaviour[1-3].

The behaviour of $\mathrm{Bi}$ has been described in the terms of its solution speciation as a function of $\mathrm{pH}$ which is well-established [4-7] and provides a first order, but simplistic, assessment of its mobility in pore solution in the regolith. Recent reviews have highlighted a lack of understanding in regards to bismuth in oxidising environments. Bismuth is estimated to have an average crustal abundance of $48 \mathrm{ppb}$ [8], but is highly fractionated across different rock types and sediments with reported concentrations from 30 ppb to greater than $20 \mathrm{ppm}$ an average $\mathrm{Bi}$ concentration in soils of $0.2 \mathrm{ppm}$ but this is difficult to reconcile with the data mentioned above. A review of bismuth values [9] concluded similar concerns and further highlighted that a background ground water concentration could not be honestly concluded especially in uncontaminated environments. This is due to no independent focused study on $\mathrm{Bi}$ concentrations in the environment and that other factors such as sampling, testing methods and protocols were not consistent.

To draw any conclusion on bismuth values, a proper understanding of the dispersion of Bi in oxidising environments must be made. This requires understanding of its low temperature aqueous chemistry and knowledge of the secondary Bi minerals that serve to buffer the element between the solid and solution states.

This study used numerous natural and synthetic bismuth mineral samples and whole rock specimens. Full spectrum quantitative X-ray Mapping (XRM) was performed on a JEOL JXA 840 SEM with a Moran Scientific energy dispersive spectroscopy (EDS) Microanalysis system operated at 20kV. A JEOL 8600 EM Probe with a combined EDS and three JEOL wavelength dispersive spectrometers (WDS's) were also used to perform trace and quantitative analysis. The analysis was undertaken at 15 $\mathrm{kV}$ and $20 \mathrm{nA}$. Drill core samples from the Mineral Hill mine site in regional NSW have been studied to determine the primary bismuth phases at this site which have been associated with a localised Au resource and then related to the known secondary expressions (Figure 1). Experiments have been carried out on a series of synthetic secondary bismuth minerals (Figure 2) to determine the chemical behaviour of these minerals by High Temperature X-ray Diffraction (HTXRD) and Thermogravimetric Analysis coupled with a Differential Scanning Calorimeter (TGA-DSC).

These experiments have provided data which can be combined with low temperature solubility studies to give an in-depth understanding into the geochemical roles of secondary bismuth minerals in the supergene environment. For the first time a series of thermodynamic data sets for major and important bismuth mineral phases have been derived. As such a series of useful geochemical models have been 
developed, which can be tailored to specific environments as needed. This information can and has been directly used to determine new exploration strategies in Australia, Soloman Islands and other localities worldwide.

\section{Acknowledgements}

IUMAS committee and AMAS committee for providing a very generous bursary to attend. Adam McKinnon from Kimberly Metals Ltd for supplying samples and mine site access.

\section{References}

1. Plimer, I.R. (1975) Wolfram Camp wolframite-molybdenite-bismuth-quartz pipes, north Queensland. In: Knight, C.L. (Ed.) Economic Geology of Australiaand Papua New Guinea - 1. Metals. AUSIMM, Melbourne, Monograph Series, 5, 760-762.

2. Angio, E.E. and Long, D.T. (Eds) (1979) Geochemistry of Bismuth. Dowden, Hutchinson and Ross, Inc., Stroudsburg, PA, USA.

3. Collins, P., Hooper, B. and Cornelius, M. (2004) Whim Creek Cu-Zn-Pb deposit, Pilbara, WA. In: Butt, C.R.M., Cornelius, M., Scott, K.M. and Robertson, I.D.M. (Eds) Regolith Expression of Australian Ore Systems. CRC

LEME, Perth, 1-3.

4. Baes, C.F. Jr and Mesmer, R.E. (1976) The Hydrolysis of Cations. Plenum Press, New York.

5. Norman, N.C. (1998) Chemistry of Arsenic, Antimony and Bismuth. Blackie, London.

6. Smith, R.M. and Martell, A.E. (1976) Critical Stability Constants. Volume 4: Inorganic Complexes. Plenum Press, New York.

7. Thurston, J.H., Swenson, D.C. and Messerle, L. (2005) Solvolytic routes to new nonabismuth hydroxy- and alkoxy-oxo complexes: synthesis, characterization and solid-state structures of novel nonabismuth polyoxo cations $\mathrm{Bi9}(3-\mathrm{O}) 8$ ( 3-OR)6 5+ (R: H, Et). Chemical Communications, 4228-4230.

8. Emsley, J. (1991) The Elements. Second edition, Oxford University Press, Oxford.

9. Filella, M. (2010) How reliable are the environmental data on 'orphan elements? The case of bismuth conentrations in surface waters. Journal of Environmental Monitoring, 12, 90-109.
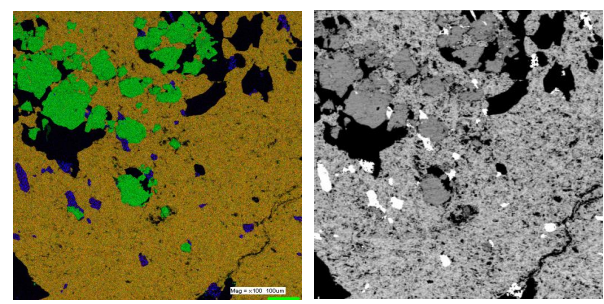

Figure 1: Left; Pseudo colour x-ray map of Mineral Hill drill core sample from a high grade Au intersection. Depicted, cosalite, $\mathrm{Pb}_{2} \mathrm{Bi}_{2} \mathrm{~S}_{5}$ (blue), pyrite, $\mathrm{FeS}_{2}$ (Green), and chalcopyrite, $\mathrm{CuFeS}_{2}$ (Yellow). Right; BSE image of the same Mineral Hill frill core sample.

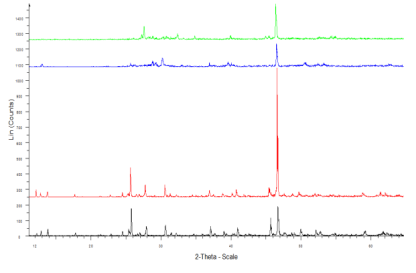

Figure 2: HTXRD analysis of cannonite, $\mathrm{Bi} 2(\mathrm{SO} 4) \mathrm{O}(\mathrm{OH}) 2$, a secondary bismuth mineral and its thermal decomposition products from $30^{\circ} \mathrm{C}$ (black), $200^{\circ} \mathrm{C}$ (Red), $400^{\circ} \mathrm{C}$ (Blue) and $600^{\circ} \mathrm{C}(\mathrm{Green})$ 